\title{
Spatial Data Transfer Standard (SDTS)
}

\section{Background}

The American National Standards Institute's (ANSI) Spatial Data Transfer Standard (SDTS) is a mechanism for archiving and transferring of spatial data (including metadata) between dissimilar computer systems. The SDTS specifies exchange constructs, such as format, structure, and content, for spatially referenced vector and raster (including gridded) data.

The SDTS includes a flexible conceptual model, specifications for a quality report, transfer module specifications, data dictionary specifications, and definitions of spatial features and attributes.

\section{Advantages}

Advantages of the SDTS include data and cost sharing, flexibility, and improved quality information and metadata, all with the potential for no loss of information during transfer. The SDTS is not vendor specific or proprietary.

\section{Status}

The SDTS was approved as ANSI/NCITS 320.1998 in June 1998. The ANSI standard covers the base standard (SDTS Parts 1 through 3) and the (SDTS Part 4) Topological Vector Profile (TVP), the first profile designed for a specific type of data.

Use of the SDTS became mandatory for Federal agencies in June 1994. At that time, Part 4 of the SDTS standard was added to FIPS 173, and the name was changed to FIPS 173-1.

The SDTS serves as the spatial data transfer mechanism for all Federal agencies and is available for use by State and local governments, the private sector, and research and academic organizations.

Part 5, Raster Profile with Extensions (RPE), was approved by the Federal Geographic Data Committee (FGDC) as an FGDC standard. Part 6, Point Profile, was approved as an FGDC standard in 1997.

\section{Implementation Support}

The U.S. Geological Survey (USGS) remains the designated maintenance authority for the base standard and SDTS Parts 4 (TVP) and 5 (RPE).

Maintenance of other profiles will be conducted by the sponsoring organization(s). The Point Profile (SDTS Part 6) is maintained by NOAA, the agency that developed and championed it through the FGDC approval process.

As the primary maintenance authority, the USGS is committed to increasing the acceptance and use of SDTS as follows:

Profile Development-A profile is a clearly defined and limited subset of the SDTS, designed for use with a specific type of data. The most effective way to use the SDTS is to first define a profile; encoding and decoding software can then be designed to handle only the options in the profile. The USGS will continue to provide technical guidance to organizations wishing to design, implement, and maintain additional SDTS profiles.

Consumer Support-The SDTS Task Force located at Mid-Continent Mapping Center provides a point of contact and a source of information about SDTS issues and data. The task force provides SDTS consumer support in the form of literature, online information, and participation in workshops, seminars, and presentations at events on national and international levels. To get assistance, send e-mail to sdts@usgs.gov.

GIS Software Vendor Support-The SDTS Task Force actively supports efforts by software vendors to add to or enhance existing SDTS capabilities in their software packages. The task force provides technical guidance and beta testing for selected software packages. Some consumers prefer to use less expensive GIS software that has comparatively less functionality, and some prefer to use packages with the greatest functionality, regardless of the cost. For these reasons, support is given to vendors at all levels of the function and cost spectrum.

Public Domain Software-The USGS offers dlgv32 software for viewing SDTS data and SDTS support software for programmers at

http://mcmcweb.er.usgs.gov/sdts/ public_domain.html. This site also includes the FIPS 123 function library with source code and Master Data Dictionary (MDD) software to create MDD transfers from ASCII input files.

User Guides - Because of the complexity of the SDTS, and to promote education, the USGS distributes articles, a list of frequently asked questions (FAQ), user guides, and training material through the SDTS Web page.

Conformance Testing - Conformance tests capture the technical description of the SDTS and measure whether or not a product faithfully implements it. Faithful implementation of the standard makes it 
possible for consumers using different software packages and data sets from different data producers to get the same consistent results. Detailed information about SDTS conformance testing is available on the SDTS Web page.

\section{Data Availability}

The US GeoData page, maintained by the EROS Data Center, contains downloadable data, information, and public domain software that is currently available at no cost to the consumer. Available data include 7.5-Minute Digital Elevation Models (1:24,000-scale), 1:2,000,000-scale Digital Line Graphs, and Large Scale Digital Line Graphs (1:24,000-scale). Geodata download statistics available through this page reflect the growing use and acceptance of SDTS data by the GIS community. To visit this site, go to http:/edcwww.cr.usgs.gov/doc/edchome/ ndcdb/ndcdb.html.

\section{Online Information}

The SDTS (FIPS 173-1, all parts) and related documentation are available in electronic form through anonymous FTP on the Internet at the following address:

ftp://sdts.er.usgs.gov/pub/sdts

User: anonymous

Password: your e-mail address

After connecting: cd pub/sdts

The OOREADME file contains information on the contents of each subdirectory.

The SDTS Web page contains a wealth of information with links to other items of interest to consumers, standards organizations, programmers, and potential developers of additional SDTS profiles. The SDTS home page can be found on the World Wide Web at

http://mcmcweb.er.usgs.gov/sdts.

\section{Sites to Visit}

SDTS Web page:

http://mcmcweb.er.usgs.gov/sdts

US GeoData page:

http://mcmcweb.er.usgs.gov/sdts/

public_domain.html

SDTS FTP site:

ftp://sdts.er.usgs.gov/pub/sdts

National Mapping Program Geospatial Standards:

http://mapping.usgs.gov/standards

\section{For More Information}

For additional information about the SDTS or how to participate in related development activities, contact:

U.S. Geological Survey

Attn: SDTS Task Force, MS 508

1400 Independence Road

Rolla, MO 65401-2602

E-mail: sdts@usgs.gov

573-308-3561

Paper copies of the SDTS are for sale from:

National Technical Information Service Computer Products Office

5285 Port Royal Road

Springfield, VA 22161

703-487-4600

Request FIPSPUB 173-1a for parts 1, 2, and 3 of the standard; and FIPSPUB 173-1b for part 4.
For information on these and other USGS products and services, call 1-888ASK-USGS, use the Ask-USGS fax-ondemand system, which is available 24 hours a day at 703-648-4888, or visit the general interest publications Web site on mapping, geography, and related topics at

http://mapping.usgs.gov/www/products/ mappubs.html.

Please visit the USGS home page at http://www.usgs.gov/.

Any use of trade, product, or firm names is for descriptive purposes only and does not imply endorsement by the U.S.

Government. 